\title{
Artigo
}

\footnotetext{
Resumo

A técnica do atendimento infantil pode ser estudada a partir do pensamento de Winnicott e de sua forma peculiar de conduzir determinados casos nos quais perceben que a interpretação encontrava-se ineficaz. Para esses casos, o autor propôs um novo tipo de manejo e condução das sessões e ressaltou a importância da estabilidade do setting para o desenvolvimento emocional. O principal objetivo deste artigo é ilustrar e ampliar a discussão do tema por meio da apresentação de um caso clínico infantil, no qual pudemos identificar a necessidade dessa postura diferenciada do terapeuta para o resultado do tratamento.

Descritores: psicanálise da criança; caso clínico; desenvolvimento emocional.
}

\section{O SETTING \\ SUFICIENTEMENTE BOM \\ E O MANEJO CLÍNICO \\ NA PSICOTERAPIA \\ INFANTIL: RELATO \\ DE CASO}

Julia Archangelo Guimarães Höfig Sandra Aparecida Serra Zanetti

DOI: http//dx.doi.org/10.11606/issn. 1981-1624.v21i1p45-62.

Psicóloga. Graduada pela Universidade Estadual de Londrina, Londrina, PR, Brasil.

- " Professora da Universidade Estadual de Londrina (UEL), Londrina, PR, Brasil. 
A primeira autora que se destacou nesses estudos foi Melanie Klein, que adotou o lúdico como a principal técnica na psicoterapia infantil. A autora, percebendo o uso que as crianças faziam da brincadeira, entendeu que nesse ato a criança estava expressando seus conteúdos, conflitos e angústias relacionados com as fantasias inconscientes. Esses conteúdos manifestados no brincar deveriam ser traduzidos e interpretados para a criança, tornando-se conscientes a ela (Ferreira \& Campos, 2014).

Kupermann (2011) relata em um artigo de caráter histórico como a clínica foi se modificando em seu modo de atuar de acordo com o tipo de paciente que recebia. Na práxis freudiana clássica, a criança era entendida como um símbolo do sexual recalcado, e as interpretações serviam como fonte de tornar consciente o que estava inconsciente. No entanto, foi-se percebendo os limites da interpretação para determinados casos graves em pacientes com traumas severos. Para estes, a associação livre e a interpretação do recalcado não surtiam efeito terapêutico. A partir disso, com estudos de autores como Ferenczi e Winnicott, estabeleceu-se uma clínica na qual se compreendia que os traumas infantis, ocorridos devido a falhas ambientais, interrompiam o percurso da organização psíquica (Kupermann, 2011).

Além de interpretar e revelar os conflitos intrapsíquicos do inconsciente infantil, Winnicott propôs um novo modo de atuação para essa modalidade de atendimento. Este modelo se baseia na compreensão do contexto ambiental e desenvolvimento emocional primitivo da criança. Portanto, não são todos os casos que devem ser conduzidos de maneira verbal, pois com alguns pacientes a interpretação e a compreensão está inabilitada e é inviável (Januário \& Tafuri, 2008).

São os apontamentos feitos por Winnicott e sua forma peculiar de conduzir determinados casos que fundamentam este artigo. Dessa forma, serão trazidos alguns conceitos cruciais para o entendimento da teoria winnicottiana sobre a importância do ambiente na constituição psíquica do sujeito. Trataremos também da forma de condução e manejo clínico para determinados casos a partir de uma revisão bibliográfica de artigos atuais. O principal objetivo deste artigo será ilustrar e ampliar a discussão do tema por meio da apresentação de um caso clínico, no qual se pôde identificar a necessidade dessa postura diferenciada do terapeuta para o resultado do tratamento, salientando os benefícios dessa vivência para a criança. 


\section{O desenvolvimento infantil em Winnicott}

Para Winnicott (1971/1975), os bebês nascem com uma tendência inata ao desenvolvimento e integração, ou seja, com uma tendência a desenvolver seu self e sua personalidade. Porém, para que consigam amadurecer emocionalmente precisam sentir-se existindo enquanto um ser, e só assim, futuramente, serão capazes de relacionar-se com o mundo de forma real. No entanto, isso só será possível mediante um ambiente proporcionado pela família que deve ser preparado para acolher essa criança quando nascer e deve estar disponível para que o que é inato do desenvolvimento possa emergir.

A criança nasce não-integrada e indiferenciada da mãe, mas com uma tendência inata ao desenvolvimento, e será a conduta suficientemente boa da mãe - ou substituta - que proporcionará esse ambiente seguro e estável, que atende às necessidades fisiológicas e emocionais do bebê, que darão base para que esta criança possa amadurecer de forma saudável (Winnicott, 1971/1975).

A falta desses cuidados iniciais pode comprometer o desenvolvimento emocional e psíquico infantil. Nas palavras de Winnicott (1988/1990b), "na ausência dos cuidados pessoais e contínuos da mãe esse desenvolvimento não pode ocorrer." (p. 90), e por consequência pode-se desenvolver um falso self como estratégia para adaptar-se a essas falhas maternas. Segundo Maggi (2007), na concepção de Winnicott, o processo de crescimento ocorre de forma gradual e deve ser compreendido como uma condição para não se colocar em risco a espontaneidade pessoal. No início a criança encontra-se em um estado de dependência absoluta de um cuidador, em que a mãe ou quem faz a função desta deve garantir todos os cuidados necessários à sobrevivência e ao investimento do bebê. A mãe (ou substituta) que se identifica com o filho em suas necessidades e o acolhe promoverá a criação de um espaço entre os dois, intersubjetivo.

Para que haja essa construção, primeiro a mãe deve contribuir com a fantasia de onipotência do bebê, de que tudo que ele necessita consegue de modo mágico. À medida que a mãe percebe que o bebê já tem condições de ir lidando gradativamente com a realidade, ela deve ceder espaço para a criança sentir e solicitar o que lhe falta, o que inaugura na criança o reconhecimento de ser dependente e o entendimento do quanto sua mãe é necessária. Durante esse processo a criança oscila entre momentos em que fantasia e outros em que percebe a realidade; une e separa-se da mãe. Se a mãe for suficientemente boa, ela se oferece para ficar no lugar que seu bebê a imaginou (Maggi, 2007).

Winnicott (1987/1994b) explica que aos poucos o bebê passará a relacionar-se com o objeto, podendo 
atacá-lo e, se isso não tiver efeitos sobre o bebê, como uma retaliação, desenvolve-se a capacidade de usar os objetos, compreendendo-o como uma entidade externa e diferenciada dele e de suas fantasias. Ou seja, à medida que o bebê vive sua espontaneidade e motilidade sem o sentimento de culpa de que com isso é capaz de destruir quem ama, não alimenta uma fantasia de que é um ser destrutivo e segue para a posição depressiva, vendo-se a si mesmo e ao outro como inteiros. A posição depressiva em Winnicott tem o caráter de possibilitar a entrada da criança no mundo real e compartilhado, ao começar a conseguir diferenciar fantasia de realidade e ir integrando-se como uma unidade. Assim irá perceber também os outros como seres inteiros e passará a desenvolver a capacidade de preocupação pelo objeto. Todo esse processo psicológico somente será possível diante de um ambiente facilitador (Winnicott, 1971/1990a).

Kahtuni (2014) explica que esse processo é estruturante da organização psíquica, e é papel da mãe sobreviver aos ataques de seu filho para que forneça um ambiente propício ao processo de integração. Se a mãe sobrevive aos ataques, a criança se acalma ao perceber que não é onipotente a ponto de destruir a mãe que ama, e isso permite a integração das partes do ego identificadas como boas ou más. A capacidade de sobrevivência da mãe pode ser traduzida em capacidade de compreensão, acolhimento e não retaliação, pois isso mostra para a criança que sua agressividade não é destrutiva.

No entanto, em casos em que houve falha ambiental nesse sentido, as pulsões destrutivas não puderam ser integradas e acolhidas. Será papel do analista fazer com que o paciente internalize experiências boas para que haja progresso no desenvolvimento que ficou estagnado (Kahtuni, 2014).

\section{Necessidade de vivenciar, presenciar e atestar}

Winnicott nunca desconsiderou a prática clássica da psicanálise: a escuta, a transferência e a interpretação. No entanto, o que este autor observou a partir de sua prática e contato com crianças é que alguns pacientes sofrem de patologias cujas raízes encontram-se em falhas no estágio primitivo do desenvolvimento, anterior ao complexo de Édipo. Nesses casos, as patologias são mais graves em função de falhas na aquisição de um selfintegrado, da consequente dificuldade 
de diferenciação entre realidade interna e externa, e em processos elaborativos da mente como a simbolização, associada à capacidade do ser humano em lidar com a frustração, ao aceitar a falta e a separação da mãe. Isso só se torna possível quando a vivência da onipotência e apresentação gradual da realidade foram oferecidas ao bebê. Dessa forma, Winnicott aponta que o mais importante é ajudar o paciente a retomar o processo de desenvolvimento de onde aconteceram essas falhas, substituindo a técnica clássica da interpretação por outra. Nesses casos, Winnicott passou a se oferecer como suporte para o paciente, participando com sua presença sensível e respeitando o ritmo de cada um (Kupermann, 2011).

Nesse tipo de manejo, de acordo com Winnicott, a interpretação fica suspensa por um tempo e proporciona-se um ambiente que se equipara com a função materna. Acolhendo-se as manifestações espontâneas do paciente, será possível que uma regressão ocorra. No entanto, esse é um aspecto positivo da regressão, que estará a favor de uma comunicação primitiva do paciente com o terapeuta que só é possível devido a uma segurança, empatia e estabilidade vivida no setting, proporcionado pelo terapeuta. Seria uma regressão há um tempo precoce do desenvolvimento, uma etapa que precisava ter sido vivenciada adequadamente, mas que não foi em razão de uma falha ambiental inicial (Telles, 2011). De acordo com Galván (2012), essa regressão está relacionada a um

retorno a uma condição anterior ao congelamento da situação da falha, na qual é essencial a adaptação do ambiente às necessidades do indivíduo como uma nova oportunidade deste encontrar a provisão ambiental adequada e, assim, descongelar a situação da falha. (p. 47)

Trata-se então, expressa a autora, de uma regressão à dependência.

Kahtuni (2014) entende que a regressão do paciente que está em análise é resultado de um processo relacional. Pacientes com grandes traumas no início da vida possuem uma dissociação do ego, ou seja, um ego bastante cindido que aceita e ao mesmo tempo rejeita a realidade, 
pois houve falhas no processo de integração da personalidade. Esses pacientes não se encaixam na classificação de neurose, pois os neuróticos são pacientes que sofrem com fantasias e conflitos inconscientes infantis. Já os pacientes regredidos sofreram perturbações reais do mundo, que foram sentidas como um choque e que distorceram o rumo do desenvolvimento psíquico. A marca psíquica deixada por esses traumas é a cisão do ego, e essa cisão resulta em uma dificuldade de lidar com os afetos ambivalentes direcionados ao objeto de amor. A pessoa permanece em uma condição de vulnerabilidade e fragilidade egoica, o que não permitirá que se estabeleça um ego integrado e verdadeiro, dando margem para a construção de um falso-self (Winnicott, 1986/1999), ou seja, um falso-eu que oculta o verdadeiro eu, deixando-o empobrecido pela falta de experiências.

Para Galván (2012), a regressão à dependência na terapia inaugura um momento de manifestação dos elementos saudáveis da personalidade, "em busca de se desfazer de uma existência baseada no falso si-mesmo e retomar o amadurecimento a partir do si-mesmo verdadeiro" (p. 47). Assim, para a autora, esse tipo de experiência só se torna possível se houver um ambiente suficientemente confiável, passível de se adaptar à necessidade do paciente e adequado para o atendimento aos pacientes que necessitam regredir à dependência. Ou seja, um ambiente "cujo parâmetro é a maternagem nos estágios iniciais da primeira infância” (p. 48).

Winnicott (1955/2000a) descreve uma série de eventos que devem ocorrer para que a regressão aconteça, cujos benefícios são a retomada do desenvolvimento e da saúde:

O fornecimento de um contexto que proporciona confiança. A regressão do paciente à dependência, com a devida percepção do risco envolvido. $\mathrm{O}$ paciente sente o eu de um modo novo, e o eu até aqui oculto é entregue ao ego total. Novo progresso do indivíduo a partir de onde o processo havia parado. Descongelamento da situaçáo da falha original. A partir da nova posiçáo de força do ego, raiva relativa à situaçáo da antiga falha, sentida no presente e explicitada. Retorno da regressáo à dependência, num progresso organizado em direção à independência. Necessidades e desejos instintivos tornados realizáveis com vigor e vitalidade genuínos. E tudo isso repetindo-se inúmeras vezes. (p. 384)

Januário e Tafuri (2008), refletindo sobre a importância da relação estabelecida entre a criança-paciente e o terapeuta, assinalam que no manejo clínico com crianças em estado de sofrimento psíquico, em alguns casos, vale muito mais que a interpretação, pois deixa emergir 
atitudes não-verbais que fortificam e estabelecem um vínculo entre o paciente e o terapeuta. Para essas autoras, seguindo o pensamento winnicottiano, isso ocorre com pacientes que ainda não se integraram e ainda não estabeleceram uma unicidade egóica.

A partir da ilustração de um caso clínico, Januário e Tafuri (2008) mostram que, diante dos sentimentos despertados na terapeuta pelo paciente, ela opta por acompanhar o sofrimento da criança, estando ao seu lado e tentando encontrar formas de contato pessoal para além da patologia apresentada, pois percebeu que qualquer contato verbal levava a criança a um estado confusional e era vivido como invasivo. Então, buscou-se primeiro estabelecer uma relação transferencial por meio de uma postura cuidadosa e silenciosa na observação da criança. Nessa vivência, conclui-se que para crianças em estado de sofrimento psíquico grave, a função de holding (adaptação ativa e completa às necessidades dela) e permissão do analista para que use seu corpo e seu olhar, permite à criança apropriar-se de suas próprias partes corporais e limites.

Winnicott (1987/1994a) afirma que o paciente vivencia o que não aconteceu, ou seja, o que não existiu psiquicamente, e encena o vazio dessa experiência que não pode ser lembrada nem esquecida. A repetição é uma demanda de integração que se volta para o ambiente na intenção de que alguém acolha essa necessidade de integração do self.

A análise, portanto, nesse ponto de vista, deve propiciar as condições que faltaram na vida desses pacientes. No setting, o terapeuta deve estar disponível para "ir sendo junto com o paciente, podendo chegar lá, diante do irreconhecível, do estranho, do absurdo" (Palhares, 2008, p. 103) e possibilitar que este revisite suas experiências não verbais e corrija falhas ambientais. $\mathrm{O}$ analista deve estar a serviço da continuidade do desenvolvimento do ser de seu paciente até que este possa ir, aos poucos, descobrindo a alteridade. O processo psicoterapêutico infantil nesses moldes é o que permite ao ser a construção de um passado, no presente.

\section{Relato clínico}

O relato trata-se do atendimento de uma menina de 5 anos de idade, a qual demos o nome fictício de Carolina, atendida num contexto de clínica-escola.

As primeiras sessões foram realizadas com a mãe, já que o pai recusou-se a participar. Lydia, nome fictício, relatou que a filha não ingeria a maioria dos alimentos, tendo uma alimentação extremamente restrita. A criança se comportava como se tivesse repúdio ou aversão em relação à comida, não conseguindo muitas 
vezes sequer olhar para o prato ou sentar-se à mesa. Na escola, Carolina alimentava-se apenas quando lhe era oferecido alimentos que gostava e, quando isso não ocorria, ela passava o dia inteiro sem comer, já que estudava em período integral.

Lydia explicou que a filha também tinha alguns rituais nas refeições. As comidas da menina não podiam ser misturadas e deviam ser cortadas em tiras. Carolina não conseguia tomar água no mesmo copo em que alguém tivesse bebido, ou usar o mesmo talher que outra pessoa tivesse usado, pois alegava sentir o gosto do alimento que a pessoa comeu. Isso nos deu a sensação de que a criança sentia que o alimento a "contaminava" quando se misturava com elementos de outras pessoas, principalmente da mãe.

Um dos alimentos que Carolina mais solicitava era o leite, porém queria que este fosse servido na mamadeira. No entanto, Lydia não queria mais oferecer a mamadeira para a filha devido a sua idade, justificando que poderia acarretar problemas dentários. Carolina ainda roia as unhas, tanto das mãos quanto dos pés, e apresentava forte ansiedade e muita dificuldade para dormir.

Lydia contou que quando Carolina nasceu engasgava e regurgitava em todas as mamadas. Em uma dessas engasgadas, aos 20 dias de vida, a situação se agravou e ela teve que ir para o hospital por falta de oxigênio. Realizados alguns exames identificou-se a existência de um desvio na 
traqueia e um trato intestinal muito apertado. Por conta disso, Carolina passou a fazer uso de medicamentos para aliviar sua dor.

Ao completar um ano, Carolina realizou vários exames para verificar como estava seu desvio e seu trato, e descobriram que ela já estava muito melhor. Depois disso, Lydia trocou Carolina de escola por causa de questões financeiras. $\mathrm{Na}$ primeira semana de adaptação, a mãe levou a mamadeira da filha, mas depois a escola proibiu por questões de higiene. Foi por volta desse período que a menina começou a se recusar a comer. Depois de 15 dias, a escola chamou a mãe para avisar que a criança não estava comendo absolutamente nada. Em casa ela também começou a recusar os alimentos.

Devido à gravidade da situação, a mãe levou a filha à pediatra aos três anos de idade, que a orientou a fazer um acompanhamento com uma nutricionista e com uma psicóloga. Durante o acompanhamento com a nutricionista, esta disse para Lydia suspender o leite da alimentação para ver se Carolina comia ou experimentava outros alimentos. Entretanto, o quadro da criança se agravou já que ela passou a rejeitar até os alimentos aos quais habitualmente comia, até que adoeceu e teve que ser internada com início de desnutrição.

Após esse episódio a mãe decidiu abandonar os acompanhamentos. No entanto, com o agravamento do caso, a pediatra de Carolina insistiu no encaminhamento psicológico, explicando para Lydia que seria somente assim que os problemas se resolveriam.

A única estratégia que Lydia conseguiu adotar foi a de castigar Carolina. Recusava-se a comprar algo que a menina pedisse, justificando que não o faria pois Carolina não estava "colaborando" quando não se alimentava. Pela mesma razão ela também não levava a filha para brincar no parquinho. Além disso, havia episódios em que Lydia tentava forçar a filha a comer algumas fatias dos alimentos e fazia com que ela ficasse sentada, de castigo, até comer algo. Carolina permanecia sentada, olhando para a comida, virando-a e mexendo com o garfo, mas não conseguia comer, então chorava e tinha crises de 
ânsia de vômito. Lydia ficava brava e fazia ameaças, mas a menina não cedia. A mãe falou que era muito difícil para ela manter uma postura calma, e que muitas vezes acabava perdendo o controle e gritando muito com Carolina por conta da alimentação. Tanto o pai como a mãe faziam chantagem emocional com Carolina, dizendo que ela os deixava muito tristes por não comer. Havia momentos, inclusive, que a mãe dizia que a abandonaria num hospital caso ela ficasse doente por não comer.

\section{O processo psicoterapêutico}

Após as entrevistas iniciais com a mãe, iniciou-se o atendimento com a criança. Em todas as sessões com a menina disponibilizou-se peças de lego, cubos, boneca, bonecos pequenos, fogãozinho de brinquedo, panelinhas, carrinhos, material gráfico, massa de modelar, copos plásticos e lenço de papel. Estes materiais ficavam visíveis para Carolina e era ela quem determinava quais iria utilizar. Os materiais de uso pessoal e gráfico ficavam guardados em uma gaveta na sala de atendimento, trancada à chave. $O$ intuito da gaveta, como de uma caixa lúdica, é o de que esta represente o mundo interno da criança (Winnicott, 1988/1990b). A cada sessão repunha-se o material gráfico que fosse necessário, tanto por ter acabado ou por solicitação da paciente, quanto por ter sido "destruído", quando o objeto passou a ser inutilizado como quando Carolina misturava todas as cores de tintas nos potes ou colocava vários lenços de papel dentro dos 
tubos de cola. Esse tipo de manejo visava ao estabelecimento de um setting suficientemente bom, adaptando-se a todas as necessidades do paciente.

Nos primeiros atendimentos, Carolina testou o ambiente, verificando o que era permitido ali ou não, buscando perceber se poderia confiar nele. A cada movimento olhava para a terapeuta, esperando uma autorização/desautorização. Suas brincadeiras consistiam em utilizar as peças de lego e fazer construções de prédios. Também tinha preferência em brincar com os bonecos, os representando como uma família, e fazia vários desenhos dela. Nesse início, os desenhos que ela considerava muito "feios" ou "estragados" eram jogados no lixo, pois não queria guardá-los dentro de sua gaveta. A terapeuta então intervinha assinalando que todos nós podemos fazer coisas que achamos feias e outras que achamos bonitas, mas que isso não tinha problema e que podíamos guardar tanto os desenhos que gostamos como os que não gostamos dentro da gaveta. Esse apontamento visou garantir a ideia de um ambiente acolhedor a tudo o que a criança poderia apresentar em termos do seu verdadeiro self.

Um dos aspectos notados pela terapeuta é que, nesses primeiros atendimentos, Carolina olhava várias vezes para o relógio e, quando questionada, comentava que queria ir ver sua mãe. Quando a terapeuta perguntava se Carolina queria ir embora, ela dizia que não, mas que queria ver se sua mãe ainda estava esperando-a. Entende-se desse fato que, provavelmente, a menina sentia medo de que sua mãe fosse embora, pois, além da mãe sempre lhe fazer ameaças de que iria abandoná-la se esta não comesse, Carolina sentia que estava "atacando" a mãe na sessão e, portanto, tinha medo que Lydia a retaliasse indo embora. Ao mesmo tempo, podemos pensar também que se tratava de um momento da terapia em que a criança ainda não tinha conseguido confiar plenamente na terapeuta e no ambiente.

Passada algumas sessões, após várias afirmações da terapeuta de que aquele espaço podia ser usado da maneira como a paciente quisesse, Carolina passou a ter preferência por atividades com tinta, cola, água e lenços de papel. De início, as atividades com a tinta eram feitas de forma bastante controlada. Colocava pequenas quantidades de tinta nas tampinhas para não pingar, sujar ou desperdiçar, conforme explicou à terapeuta. Aos poucos, percebendo que ela poderia confiar e fazer o que quisesse, começou a deixar alguns pingos de tinta cair na mesa. Olhava para a terapeuta para ver sua reação e, percebendo que ela realmente autorizava esse tipo de comportamento, começou a experimentar outros tipos de vivência com a tinta, esparramando-a pela mesa, fazendo várias misturas com água e cola e utilizando os dedos e as mãos para manusear suas misturas. 
Com o tempo, Carolina passou a utilizar todos os potes de tinta levados em cada sessão, misturando-os, espalhando pela mesa e pelo chão da sala. Junto a isso também utilizava muita água e cola, adicionando-os à mistura de tinta e esparramando-os pela sala também. As sessões passaram a se constituir dessas vivências com esses materiais, já que Carolina não realizava nenhum outro tipo de atividade. Portanto, as sessões eram cheias de experimentações, que representavam, supomos, alagamentos na sala e afogamentos dos pedaços de papel, já que ela os afundava nas misturas de tinta, água e cola. Em seguida, utilizava todo lenço de papel disponível para absorver a água esparramada. Como manejo, a terapeuta permitia todos esses tipos de brincadeiras e permanecia disponível para a menina utilizar-se dela como quisesse. Em alguns momentos, a criança mandava bastante na terapeuta ou tentava "destruí-la", sujando-a com essas misturas de tinta e água propositalmente, as quais jogava e espirrava para acertar a terapeuta. Entendemos que na transferência essa vivência representava a necessidade de usar o objeto impiedosamente, sem retaliações. Após dois meses em que as sessões eram utilizadas somente com essas vivências com as tintas, alguns outros movimentos foram aparecendo. Um deles foi com a utilização de caixas (caixa da massa de modelar, da tinta, do lenço) para fazer construções. Outra atividade foi a de contornos, como contornar os pés e as mãos. Compreende-se que quando ela fazia isso, representava as falhas constitutivas em termos de delimitações de seu self, reforçando bordas ou limites da construção corporal. Outra atividade que se seguia a essas era recortar os pedaços de corpos ou as caixas e colá-los juntos, com muita cola, formando "bonecas" ou pessoas, o que corroborava a nossa hipótese.

Posteriormente, ela resolveu montar circuitos na sala de atendimento, planejando alguns caminhos, delimitando percursos e colocando obstáculos, divertindo-se com a simbolização de sua construção corporal. Aos poucos ela foi tornando os circuitos mais complexos, deixando-os mais difíceis para atravessar, e também experimentando algumas experiências com barulhos com 
os materiais da sala. Compreendemos isso como, novamente, uma tentativa de explorar o ambiente, testando a capacidade da terapeuta de estar inteiramente disponível para ela. Em alguns momentos de seus circuitos, a terapeuta dizia que iria ajudá-la segurando sua mão para que não caísse ou se machucasse, o que contribuiu para que Carolina se sentisse cuidada e amparada para poder explorar e vivenciar sua motilidade e espontaneidade.

Outro período desse processo de retomada das falhas do ambiente no desenvolvimento psíquico da criança apareceu quando ela começou a querer brincar de apagar a luz da sala e de esconde-esconde com a terapeuta. Entendemos esse movimento como uma possibilidade que surgia de brincar com a ideia de estar só, intercambiando momentos de presença e ausência do objeto, finalmente adentrando o período de dependência relativa, quando o outro começa a ganhar estatuto de outro. Aos poucos, essa brincadeira se tornou frequente e um modo de se despedir da terapeuta, encenando um ritual ao final das sessões.

Nessa fase ela ainda começou a fazer desenhos e produções com a massinha, montando bolinhos e enfeitando-os. Seus bolos começaram a ganhar uma forma mais complexa e ela passou a dedicar mais tempo da sessão para confeccioná-los.

\section{Análise e discussão do material clínico}

Nesse caso, as primeiras intervenções da terapeuta partiram no sentindo de orientar os pais a ter atitudes mais acolhedoras e compreensivas em relação ao problema da filha e para que não fossem punitivos e retaliadores, pois se acredita que isso só contribuiu para o aumento da ansiedade da criança e sua identificação com seu lado destrutivo. Compreendemos que o que a menina apresentava não era uma birra em relação aos horários da refeição, e sim um medo, uma angústia em relação à comida, fruto das fantasias persecutórias alimentadas no início de sua vida, agravadas pela deformidade fisiológica que a impossibilitava de ter uma experiência satisfatória com a amamentação.

Além disso, uma hipótese, pelo modo como a mãe se apresentou, é que o ambiente vivenciado pela menina nos primeiros anos de vida não foi um ambiente capaz de acolher as angústias, a destrutividade e 
os movimentos espontâneos dela, tal como Winnicott (1958/2000b) preconiza. Sem essa função materna suficientemente boa, a criança não conseguiu desenvolver seu verdadeiro selfe integrar-se. A falta de pessoas com quem estabelecer vínculos seguros e confiáveis, assim como ambiente previsível e constante, pode levar a criança a ter uma grave cisão da personalidade (Winnicott, 1942/1982).

Além disso, Carolina possuía a peculiaridade do desvio na traqueia, o qual, provavelmente, não foi seguido de uma continência das sensações de desconforto e dor que a criança tinha, o que faz pensar que ela identificou-se com a fantasia de que era retaliada ao alimentar-se por ser destrutiva ao usufruir do leite. Dessa maneira, Carolina encontra como mecanismo de defesa a projeção de sua destrutividade na comida, passando a necessitar de total controle sobre o que estava sendo ingerido.

Ao longo das sessões fica claro que Carolina passou a poder vivenciar seu verdadeiro self, experimentando sua motilidade e expressando sua agressividade. Para isso, concebemos que primeiramente a criança teve que regredir ao estágio do desenvolvimento em que ocorreu a falha no ambiente para poder revivenciá-lo. Essa regressão só foi possível porque foi tomado o devido cuidado de providenciar um setting que se adaptasse completamente às necessidades da criança, tal como uma mãe suficientemente boa (Winnicott, 1942/1982). Por meio desse processo de regressão, buscando o descongelamento de elementos saudáveis da personalidade, como aponta Galván (2012), foi possível retomar aspectos muito primitivos da constituição da subjetividade, no qual a condução da terapia deve ser da ordem do acolhimento de um verdadeiro self em detrimento da interpretação. Vivencia-se o indizível, o caos e a angústia, e o manejo principal está na sobrevivência do terapeuta em possibilitar essas vivências e ter condições de suportá-las igualmente, disponibilizando esse espaço em sua mente, o que sustenta o setting e o faz sobreviver a essa experiência.

Segundo Winnicott (1942/1982), as crianças só depositarão seu ódio e agressão no meio que conhecem e confiam, pois sabem que o retorno desse ódio e violência do meio não retornará para elas. Um bom ambiente será o capaz de tolerar essa agressividade, e o adulto deve oferecer sua presença com a intenção de acolher essas demandas emocionais.

Percebe-se que no começo não houve relação alguma com um objeto, estando a terapeuta ali apenas como uma extensão do corpo 
da paciente, auxiliando-a a pegar os materiais e atender suas necessidades, proporcionando a sustentação de um ambiente suficientemente bom. Nesse sentido, parece visível a capacidade da criança de utilizar-se do setting visando à regressão ao estado de dependência, em que há uma relação mágica com o ambiente, pois quando o terapeuta adapta-se às necessidades do paciente promove a ilusão da onipotência. Aos poucos, ao começar a se integrar, delimitando seu selfe conferindo ao outro a existência de outro (posição depressiva), passou a elaborar esse processo por meio das atividades de junção das partes do corpo e dos contornos de suas mãos e pés. Nesse sentido, também passou a brincar de esconde-esconde, que diz respeito a uma atitude de legitimar a existência do outro - ao encontrá-lo - e na capacidade de estar só - ao esconder-se -, próprios de uma criança que começou a se perceber como um objeto integrado sem tantas angústias e sentimentos de culpa em relação a isso. As brincadeiras de confeccionar bolos também apontam para a ideia de que ela estava procurando retomar a fase de entrada na posição depressiva, já que entendemos que o processo de desenvolvimento havia estacionado antes da vivência dessa fase. Assim, o bolo era como uma tentativa de reparação, depois de ter podido viver toda a angústia ligada as suas fantasias de destrutividade e suas ansiedades derivadas delas.

Concluindo, entendemos que a condução da terapia possibilitou à criança retomar suas principais angústias e ansiedades iniciais, e elaborá-las para seguir seu processo de desenvolvimento, integrando-se e podendo com isso perceber o outro sem tanto receio de tê-lo destruído, já que, inclusive, esse outro se mostra também inteiro e não destruído pela criança.

Tal como preconizam Januário e Tafuri (2008), Kupermann (2011) e Palhares (2008), entende-se que essa evolução no caso só foi possível devido ao manejo realizado pela terapeuta em aguentar e acolher os momentos iniciais da regressão da menina, estando ali silenciosamente, com sua presença sensível, respeitando as manifestações da paciente. A interpretação perde nessas circunstâncias seu estatuto terapêutico, ao contrário, é vista pelo paciente como uma intrusão em seu processo de continuar a ser.

Ao longo do atendimento alguns sintomas desapareceram, como o de roer as unhas e a dificuldade que ela tinha para dormir, e outros foram cedendo, como a diminuição dos rituais para se alimentar, de usar um copo ou talher já usado por alguém antes e a impossibilidade de ingerir mais alimentos durante o dia. Após 10 meses de tratamento, 
a criança encontrava-se com vontade de experimentar novos alimentos, vivenciando com prazer o cheiro dos alimentos e se apresentando muito menos ansiosa. Vale acrescentar que, como se percebeu que a mãe apresentava dificuldades com a maternidade, ela foi encaminhada para terapia individual, e mantiveram-se sessões regulares de escuta e orientação. Entendemos que certamente isso contribuiu para o bom andamento do processo terapêutico com a criança, principalmente na manutenção de suas conquistas no setting.

\section{Considerações finais}

Percebeu-se que nesse caso foi de suma importância a sensibilidade da terapeuta em compreender a necessidade da criança, que era poder ter um espaço no qual tivesse a oportunidade de vivenciar experiências primitivas e constituintes que não puderam ser expressas e experimentadas anteriormente de forma saudável. Essa compreensão acerca do manejo adequado pelo caso se deu pela observação dos tipos de brincadeiras escolhidos pela criança, e também pela percepção de que, quando indagada sobre algo, a menina sentia-se paralisada e não respondia mais para a terapeuta.

A intervenção que a terapeuta fez de acolher as produções que a criança descrevia como "feias" e que queria descartar, dizendo que não teria problema guardá-las já que todos possuímos e fazemos tanto coisas feias como bonitas, inaugurou e abriu espaço para dizer que se aceitava tudo o que vinha dela, uma aceitação incondicional, liberando a possibilidade dela explorar o setting e experimentar a si mesma, pois no início da vida o "eu sou" não significa nada, a não ser que se seja com um outro que testemunha sua existência e confere valor a ela.

Com a postura e manejo da terapeuta apresentados foi possível que o setting se mantivesse estável, dando sustentação emocional e segurança, possibilitando a regressão à dependência e a expressão de vivências inconscientes e a sustentação de um verdadeiro self.

Finalmente, ressaltamos a importância das supervisões clínicas para que a terapeuta tivesse um espaço para expressar seus sentimentos, raivas e angústias vividas no setting, para que retornasse às sessões com o psiquismo capaz de suportar as manifestações da paciente e não a retaliasse, sabendo da importância dessa sobrevivência para o processo maturacional da criança.

GOOD ENOUGH SETTING AND CLINICAL HANDLING IN CHILD PSYCHOTHERAPY: A CASE STUDY

\section{Abstract}

The technique of child clinical care can be studied from the theory developed by Winnicott and his peculiar way of conducting some cases in which he realized that the interpretation was ineffective. In these cases, the author proposed a new form of handling and conduction 
during sessions and stressed the importance of setting stability for emotional development. The main objective of this article is to illustrate and expand the discussion about the topic, through the presentation of a child's clinical case, in which the need of this differentiated therapist's stance was identified and requested for the result of treatment.

Index terms: child psychoanalysis; clinical case; emotional development.

\section{EL SETTING SUFICIENTEMENTE BUENO Y EL MANEJO CLÍNICO EN LA PSICOTERAPIA INFANTIL: RELATO DE CASO}

\section{RESUMEN}

La técnica de atendimiento infantil puede ser estudiada a partir del pensamiento de Winnicotty de su manera peculiar de conducción de algunos casos en los cuales percibió que la interpretación se encontró ineficaz. Para estos casos, el autor propuso un nuevo tipo de manejo y conducción de las sesiones y destacó la importancia de la estabilidad del setting para el desarrollo emocional. El principal objetivo de este articulo es ilustrar y ampliar el debate del tema mediante la presentación de un caso clínico infantil en lo cual se identificó la necesidad de una postura diferenciada del terapeuta para el resultado del tratamiento.

Palabras clave: psicoanálisis del niño; caso clínico; desarrollo emocional.

\section{REFERÊNCIAS}

Ferreira, L. J. S., \& Campos, M. (2014). O brincar e sua função no processo analítico infantil. Connection line, (11).

Galván, G. (2012). O conceito de regressão em Freud e Winnicott: algumas diferenças e suas implicaçôes na compreensão do adoecimento psíquico. Winnicott e-prints, 7(2), 38-51.

Januário, L. M., \& Tafuri, M. I. (2008). O olhar e o corpo na relação transferencial com uma criança em sofrimento psíquico grave. Estilos da Clínica, 13(25), 192209. doi: http://dx.doi.org/10.11606/issn.1981-1624.v13i25p192-209

Kahtuni, H. C. (2014). O engano da analista e seus desdobramentos. Psicologia Revista: Revista da Faculdade de Ciências Humanas e da Saúde, 15(1), 77-108.

Kupermann, D. (2011). A criança, o infantil e o que o psicanalista (não) sabe. Estilos da Clinica, 16(2), 324-337. doi: http://dx.doi.org/10.11606/issn.1981-1624. v16i2p324-337

Maggi, N. (2007). O espaço potencial de criatividade em crianças que experimentam situaçôes de privação. Estilos da Clínica, 12(22), 158-175. doi: http://dx.doi. org/10.11606/issn.1981-1624.v12i22p158-175

Palhares, M. do C. A. (2008). Transferência e contratransferência: a clínica viva. Revista Brasileira de Psicanálise, 42(1), 100-111.

Telles, K. K. P. (2011). O manejo terapêutico em Winnicott: a clinica contemporânea. (Tese de doutorado). Universidade Estadual Paulista, Faculdade de Ciências e Letras de Assis, São Paulo.

Winnicott, D. W. (1975). O brincar e a realidade. Rio de Janeiro, RJ: Imago. (Trabalho original publicado em 1971) 
Winnicott, D. W. (1982) A criança e seu mundo. Rio de Janeiro, RJ: Imago. (Trabalho original publicado em 1942)

Winnicott, D. W. (1990a). A posição depressiva. In D. W. Winnicott, Natureza humana (pp. 89-103). Rio de Janeiro, RJ: Imago. (Trabalho original publicado em 1971)

Winnicott, D. W. (1990b). Natureza humana. Rio de Janeiro, RJ: Imago. (Trabalho original publicado em 1988)

Winnicott, D. W. (1994a). O medo do colapso. In D. W. Winnicott, Explorações psicanaliticas (Vol. 2, pp. 70-76). Porto Alegre, RS: Artes Médicas. (Trabalho original publicado em 1987)

Winnicott, D. W. (1994b). Sobre o uso de um objeto. In D. W. Winnicott, Exploraçōes psicanaliticas, (Vol. 2, pp. 170-193). Porto Alegre, RS: Artes Médicas. (Trabalho original publicado em 1987)

Winnicott, D. W. (1999). Tudo começa em casa. São Paulo, SP: Martins Fontes. (Trabalho original publicado em 1986)

Winnicott, D. W. (2000a). Aspectos clínicos e metapsicológicos da regressão dentro do setting analítico. In D. W. Winnicott, Textos selecionados: da pediatria à psicanálise (pp. 374-392). Rio de Janeiro, RJ: Imago. (Trabalho original publicado em 1955)

Winnicott, D. W. (2000b). Desenvolvimento emocional primitivo. In D. W. Winnicott, Textos selecionados: da pediatria à psicanálise (pp. 218-232). Rio de Janeiro, RJ: Imago. (Trabalho original publicado em 1958) julia.a.g@bol.com.br

Rua Paranaguá, 539 86020-030 - Londrina - PR - Brasil.

sandra.zanetti@gmail.com Rodovia Celso Garcia Cid/Campus Universitário da UEL 86.057-970 - Londrina - PR - Brasil. 